\title{
Application of Enzymes for the Reduction of PFI Revolutions in the Secondary Pulping Process and Characteristics of Thermomechanical Pulp
}

\author{
Shuai Wu, Xiaojuan Ma, Shilin Cao, Lihui Chen, Liulian Huang, Fang Huang * \\ Three enzymes, mannanase, xylanase, and cellulase, were applied for \\ hydrolysis of thermomechanical pulp (TMP) primary discharge prior to PFI \\ refining, aiming to study the effect of enzymatic hydrolysis on the required \\ number of PFI revolutions. The quantity of reducing sugar was used as an \\ indicator for enzyme hydrolysis efficiency. Then, under the optimized \\ enzyme loading, treated and un-treated pulp were refined with different \\ $\mathrm{PFI}$ revolutions. Subsequent fiber characteristics, such as fiber length and \\ fines content were examined. Under the optimized enzyme loadings and \\ a given $20000 \mathrm{PFI}$ revolutions, in comparison with the control pulp, \\ mannanase and xylanase pre-treatment could save PFI refining \\ revolutions by $20 \%$ and $25 \%$, respectively. There was no significant \\ energy savings for the cellulase-treated pulp. During the hydrolysis, the \\ enzyme broke down TMP fibers into shorter pieces and yielded more fines \\ than the control pulp. Among the three enzymes, cellulase showed the \\ highest efficiency in fiber breakdown, mannanase in the middle, xylanase \\ the lowest. Longer hydrolysis time (more than one hour) had no evident \\ effect on the pulp freeness reduction and reducing sugar production. \\ Among the three enzymes, under the optimized enzyme loading, cellulase \\ was the most efficient for enhancing production of reducing sugars.
}

Keywords: Enzyme; TMP; Refining energy

Contact information: College of Material Engineering, Fujian Agricultural and Forestry University, Fuzhou, Fujian, 350108, China; *Corresponding author: huangfanghg@gmail.com

\section{INTRODUCTION}

In mechanical pulping processes, such as thermomechanical pulping (TMP), the woody raw material is mechanically disintegrated into pulps with high content of fines, bulk, and stiffness. Although these fibers are useful for producing different grades of papers, the main disadvantage of mechanical pulping is high-energy consumption (Bhat 2000). During recent decades, with the depletion of fossil fuels and the increasing demand for energy, electrical energy has become a costly commodity. Thus, pursuing energy savings without sacrificing pulp quality is a common focus in the pulp and paper industry (Bajpai et al. 2006).

Recently, much research has been devoted to finding new technologies in order to reduce the energy demand in mechanical refining without any adverse effects on paper physical strength properties (Bhardwaj et al. 1996). Attempts to reduce the energy required to prepare TMP, for example, include application of axial pre-compression to wood chips to create microfractures between S1/S2 cell wall layers (Frazier et al. 1982); pre-treatment with chemicals (e.g. sodium sulfite) (Richardson 1996); application of enzymes as an intermediate step prior to secondary refining (Mansfield et al. 1999; Hart et al. 2009; Setliff et al. 1990; Richardson et al. 1998; Pere et al. 2000; Petit-Conil et al. 2005a,b); and enzyme 
pre-treatment of the chips prior to primary refining (Petit-Conil et al. 2005a,b; Lei et al. 2008).

Enzymes are complex protein molecules that act as catalysts speeding up chemical reactions. The enzymes were used to degrade wood polymers because they could accelerate the hydrolysis of cellulose/hemicellulose or oxidization and depolymerisation of lignin, which may facilitate the separation of fibers from each other. In the course of the enzymatic hydrolysis, the cellulose/hemicellulose are partly degraded into polysaccharides or mono sugars (reducing sugars). As a biotechnology, enzymes therefore have the potential to increase the quality and supply of feedstock for pulp and paper, reduce manufacturing cost and environmental impacts, and create novel high-value products. As such, enzymes, especially cellulase and hemicellulase, have been widely used in the wood chip/pulp treatment for energy saving in TMP pulping process. Pere et al. (2007) applied a certain cellulase mixture in TMP softwood chip pre-treatment and obtained up to $20 \%$ energy saving, and the strength of pulp properties were also increased. Further research indicated that enzymatic pre-treatment of wood chips using xylanases showed significant energy savings up to $26 \%$ when the raw material used was a hardwood (poplar and aspen) (PetitConil et al. 2005b). Similarly, energy savings in TMP production were observed when wood raw material was pre-treated with pectinases and proteases (Peng et al. 2005).

Although enzyme pre-treatment has brought reasonable success at energy saving for TMP pulping process, significant technical details have prevented commercial application of this method. For example, high operational temperatures in the case of intermediate stage tend to denature the enzyme and reduce its efficacy. Excessively long pre-treatment time also leads to limited energy reduction (Hart et al. 2009).

As discussed earlier, in previous research the enzymatic pretreatment has been directly conducted on the woodchips in the TMP pulping. The efficiency in this process was relatively low, since this pretreatment tends to be time-consuming and the biodegradation was not uniform in the woodchips. In the current work, three different enzymes, mannanase, xylanase and cellulase, were applied in TMP primary discharge pulp prior to PFI refining, aiming to study the effect of enzymatic hydrolysis on TMP pulp properties. Application of enzymes on the TMP primary discharged pulp rather than the woodchips would evidently increase the efficiency of the enzymatic pretreatment. In the first stage of this study, optimized dosages were explored for each enzyme in order to maximize energy savings. Hydrolysis filtrate was collected for reducing sugar analysis. The quantity of reducing sugar was used as an indicator (or reference) of enzyme hydrolysis efficiency. In the second stage, under the optimized enzyme loading, treated and un-treated pulp were refined with different PFI revolutions. The effect of hydrolysis time and pulp water retention value was also studied at this optimized enzyme loading. Subsequent fiber and pulp characteristics, such as fiber length, fines content and pulp strength were examined in this study. This research could afford useful data for selection of the enzymes for the TMP pulping applications.

\section{EXPERIMENTAL}

\section{Materials and Preparation}

TMP pulp: $100 \%$ black spruce TMP pulp was collected from the primary refiner discharge from Irving Pulp \& Paper, Saint John, NB (Canada). The pulp dryness was 
$71.8 \%$ (TAPPI Method T210 cm-03) and CSF freeness was $720 \mathrm{~mL}$ (TAPPI Method T227 om-09). It contained 40.86\% rejects (TAPPI Method T278 sp-09).

\section{Chemical Composition Analysis}

Basic chemical compositions including $\alpha$-cellulose, hemicellulose, Klason lignin, and ash content were analyzed on the TMP samples. $\alpha$-Cellulose and ash contents were obtained according to TAPPI Methods T429 cm 10 and T211 om-07. Klason lignin and acid soluble lignin contents were analyzed based on literature procedures (Huang et al. 2011). In brief, the pulp sample was treated with $72 \mathrm{wt} \%$ sulfuric acid for $4 \mathrm{~h}$ at $30^{\circ} \mathrm{C}$ and then diluted to $3 \mathrm{wt} \%$ sulfuric acid using deionized water and subsequently autoclaved at $121{ }^{\circ} \mathrm{C}$ for $1 \mathrm{~h}$. The resulting solution was cooled to room temperature, and the precipitate was filtered, dried, and weighed to get the Klason lignin content. The filtrate was used for the detection of sugar composition by high-performance anion exchange chromatography with pulsed amperometric detection (HPAEC-PAD), and acid soluble lignin was measured by ultraviolet (UV) spectroscopy. The hemicellulose contents were calculated from the sugar profiles analyzed with a HPAEC-PAD, as described in the literature (Sluiter et al. 2008).

\section{Enzyme Preparation}

Mannanase, xylananse, and cellulase were provided by Novozyme Inc. (USA). Each enzyme had its own applicable $\mathrm{pH}$ and temperature as listed in Table 1. The initial $\mathrm{pH}$ of water-soaked pulp was roughly 5.5. Diluted reagent grade $\mathrm{HCl}$ or $\mathrm{NaOH}$ was used to adjust the $\mathrm{pH}$ accordingly.

Table 1. Applicable Temperature and pH of Enzymes

\begin{tabular}{|l|c|c|}
\hline & Applicable Temperature $(\stackrel{\circ}{ } \mathrm{C})$ & Applicable $\mathrm{pH}$ \\
\hline Mannanase & 65 to 85 & 8.0 to 9.0 \\
\hline Xylanase & 40 to 70 & 4.0 to 6.0 \\
\hline Cellulase & 40 to 60 & 8.0 to 9.0 \\
\hline
\end{tabular}

\section{Enzyme Activity Determination}

Cellulase activity in the commercial enzyme was tested by the method described by Adney and Baker (1996). Xylanase and mannanase activities were measured by reducing sugar activity from birch wood xylan (Bailey et al. 1992) and locust bean gum (Rättö et al. 1998), respectively. One international unit enzyme (IU) is defined as the amount of enzyme necessary to produce of 1 micromole product per minute. The enzyme activities obtained are listed in Table 2.

Table 2. Enzyme Activity

\begin{tabular}{|l|c|}
\hline & Enzyme activity (IU/mL) \\
\hline Mannanase & 5120 \\
\hline Xylanase & 5460 \\
\hline Cellulase & 724 \\
\hline
\end{tabular}




\section{Enzymatic Hydrolysis}

To simplify the hydrolysis procedures, the average values of applicable $\mathrm{pH}$ and temperature range were adopted for each enzyme. According to enzyme activity, appropriate enzyme dosages were applied in each hydrolysis; $40 \mathrm{~g}$ of o.d. pulp was made into a solution of $5 \%$ consistency with demineralized water. This solution was brought to the proper $\mathrm{pH}$ with a dilute $\mathrm{HCl}$ solution or a dilute $\mathrm{NaOH}$ solution when necessary. This was prepared within a plastic bleaching bag. After adding the appropriate amount of the enzyme solution, the plastic bags were thermo-sealed and placed in a hot water bath at a given temperature. Initial hydrolysis time was chosen to be one hour. During this time, bags were vigorously mixed by hand every ten minutes to ensure uniform distribution of enzyme throughout the hydrolysis.

Control pulps were prepared at different enzyme condition (Table 3) with the exception of enzyme addition in order to eliminate the possible effects of $\mathrm{pH}$ adjustments alone.

At the end of the hour, bags were removed from the hot water bath and placed in a pot of boiling water for ten minutes to deactivate the enzyme. Pulps were then filtered and a $100 \mathrm{~mL}$ filtrate sample was kept for reducing sugar analysis. The pulp sample was ready for PFI milling work-up. Pulp hydrolysis conditions are listed in Table 3.

Table 3. Hydrolysis Conditions

\begin{tabular}{|l|c|c|c|c|}
\hline & Temperature $(\stackrel{\circ}{\circ})$ & $\mathrm{pH}$ & Time $(\mathrm{min})$ & Consistency $(\%)$ \\
\hline Mannanase & 75 & 8.5 & 60 & 5 \\
\hline Xylanase & 60 & 5.0 & 60 & 5 \\
\hline Cellulase & 50 & 8.5 & 60 & 5 \\
\hline
\end{tabular}

\section{Reducing Sugar Determination}

The reducing sugar was measured by the method described by Miller (1959). Reducing sugar in the filtrate was first color-reacted with dinitrosalicylic acid (DNS). The absorbance of this filtrate was then measured by a spectrophotometer (Multon Roy, Spectronic 1001 Plus). The quantity of reducing sugars in the filtrate was obtained by the spectrophotometric calibration curve of standard sugars, i.e. D-(+)-mannose, D-(+)glucose, and $\mathrm{D}$-xylose. The unit of reducing sugar was then converted to monosugar weight per $1 \mathrm{~g}$ o.d. pulp, i.e. $\mathrm{mg} / 1 \mathrm{~g}$ o.d. pulp.

\section{Refining}

Pulp obtained after the hydrolysis treatment was first disintegrated at 15000 revolutions in a standard disintegrator (TAPPI Method T205 sp-06). Disintegrated pulp was made into a $7 \mathrm{~L}$ suspension. Consistency of this suspension was checked in triplicate before filtering the required amount to obtain $30 \mathrm{~g}$ o.d. pulp. Leftover pulp was used for initial CSF measurement and FQA analysis.

The thickened pulp was brought to $300 \mathrm{~g}$ with tap water in order to have a $10 \%$ consistency as required by the TAPPI Method (T248-sp 08). This pulp was placed in a PFI mill (NORAM CA318, Canada) and beaten to different revolutions between 5000 and 20000. The accepted pulp was taken for freeness. The FQA measurements were conducted only for the 20,000 PFI revolutions pulps.

Length weighted mean fiber length and length weighted mean fines percent were measured in a Fiber Quality Analyzer (FQA, Optest, Canada) following all relevant 
instructions for sampling provided by the operating manual. Triplicate measurements were conducted for all tests, and a mean value was reported. The error margin associated with the analysis was $\pm 5.0 \%$.

\section{Water Retention Value Measurement}

The water retention value measurements were conducted for all the 20,000 PFI revolution pulps based the literature method (Allender and Waterhouse 1986). Briefly, a fiber mat was formed (using a pulp slurry of $52 \mathrm{~mL}$ at $0.25 \%$ consistency) onto the 100 mesh wire in the centrifuge tube and centrifuged (IEC UV Centrifuge, Diameter $60 \mathrm{~cm}$ ) at $2500 \mathrm{rpm}$ for 15 minutes. The centrifuged samples were weighted before and after drying overnight at $105^{\circ} \mathrm{C}$. The WRV is expressed as the percentage of the gram of water per gram of oven-dry pulp, as indicated in the following equation,

$$
\text { Water retention value }=\frac{W_{1}-W_{2}}{W_{2}} \times 100 \%
$$

where $W_{1}$ is the sample weight before drying and $W_{2}$ is the sample weight after drying.

\section{Tensile Strength Analysis}

The tensile strength analysis was performed for all the 20,000 PFI revolution pulps based the TAPPI method (TAPPI T220-sp 01). The tensile strength of the pulp was characterized as tensile index (N.m/g) in this research.

\section{RESULTS AND DISCUSSION}

\section{Chemical Composition}

The chemical composition analysis of black spruce TMP pulp is listed in Table 4. The $\alpha$-cellulose and hemicellulose contents in TMP pulp are close to the data of softwood mentioned in the literature (Huang et al. 2011). In addition, among the hemicelluloses, the mannan, xylan and glucan are most abundant carbohydrates, as shown in Table 4.

Table 4. Chemical Composition Analysis of the TMP Pulp (wt\% on the o.d. sample)

\begin{tabular}{|c|c|c|c|c|c|c|c|c|}
\hline \multirow{2}{*}{ a-Cellulose } & \multicolumn{4}{|c|}{ Hemicellulose } & \multicolumn{3}{c|}{ Lignin } & \multirow{2}{*}{ Ash } \\
\cline { 2 - 9 } & Arabinan & Galactan & Glucan & Xylan & Mannan & $\begin{array}{c}\text { Acid-insoluble } \\
\text { (Klason lignin) }\end{array}$ & $\begin{array}{c}\text { Acid } \\
\text { soluble }\end{array}$ & \\
\hline 44.6 & 1.4 & 2.1 & 2.1 & 6.4 & 8.5 & 25.5 & 1.1 & 0.8 \\
\hline
\end{tabular}

\section{Optimization of Enzyme Dosage}

In this stage, different enzyme loadings were applied in the hydrolysis to get the maximized freeness reduction at 20,000 PFI revolutions. CSF was used as a benchmark to guide the selection of optimal enzyme dosages. Combining with the reducing sugar, the results could help us to optimize the enzyme loading in the hydrolysis.

Figure 1 shows the mannanase dosage vs. CSF freeness at 20000 PFI revolutions. The mannanase loading ranged from 0 to $1000 \mathrm{IU} / \mathrm{g}$. It can be observed that for the same PFI refining revolutions, an enzyme dosage of $300 \mathrm{IU} / \mathrm{g}$ could maximally reduce pulp CSF freeness by $12.4 \%$. Figure 1 also shows the mannanase dosage vs. reducing sugar in the hydrolysis. The reducing sugar rose rapidly when the enzyme loading exceeded $200 \mathrm{IU} / \mathrm{g}$, 
then increased slowly with further increasing of enzyme loading. When the enzyme loading was increased from $300 \mathrm{IU} / \mathrm{g}$ to $1000 \mathrm{IU} / \mathrm{g}$, the increase of reducing sugar was very limited $(\sim 10 \%)$. Combining pulp freeness and reducing sugar curves in this figure, the optimized mannanase dosage should be around $300 \mathrm{IU} / \mathrm{g}$, which could maximally reduce pulp freeness at 20000 PFI revolutions.

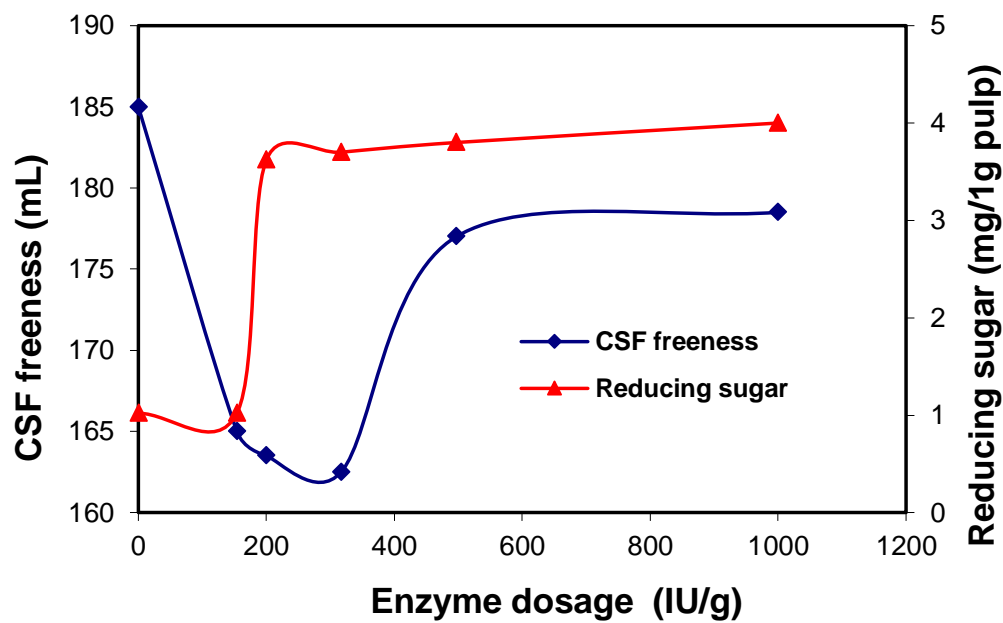

Fig. 1. Effect of mannanase loading on pulp freeness and reducing sugar at $20000 \mathrm{PFI}$ revolutions

In the xylanase dosage $v s$. CSF freeness relation in Fig. 2: for the same PFI refining revolutions, enzyme dosage $1000 \mathrm{IU} / \mathrm{g}$ could maximally reduce pulp CSF freeness by $27.0 \%$. From Fig. 2, it can also be seen that reducing sugar rose continuously with increases of enzyme loading. Considering the combination of pulp freeness and reducing sugar, the optimized xylanase dosage should be around $1000 \mathrm{IU} / \mathrm{g}$, which could reduce pulp freeness and economize enzyme expense.

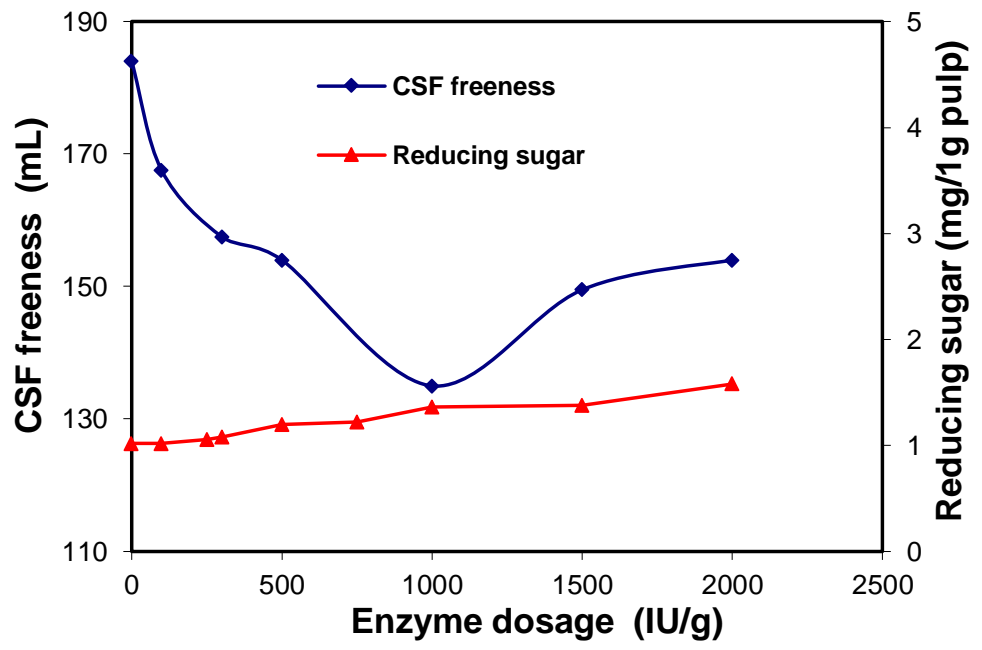

Fig. 2. Effect of xylanase loading on pulp freeness and reducing sugar at $20000 \mathrm{PFI}$ revolutions

The relation of cellulase vs. CSF freeness is shown in Fig. 3. For the same PFI refining revolutions $(20,000)$, pulp freeness decreased continually as the enzyme dosage was increased from $0 \mathrm{IU} / \mathrm{g}$ to $20 \mathrm{IU} / \mathrm{g}$. After reaching a dosage of $20 \mathrm{IU} / \mathrm{g}$, pulp freeness 
increased rapidly. This curve tendency is very similar to that observed in Fig. 1. From Fig. 3 , a cellulase loading of $20 \mathrm{IU} / \mathrm{g}$ can maximally reduce pulp CSF freeness by $13.0 \%$. It can be noticed that the reducing sugar in Fig. 3 rose continually with the increase of enzyme loading. The curve tendency was almost linear, which implies that cellulase is an efficient enzyme for sugar production during pulp hydrolysis.

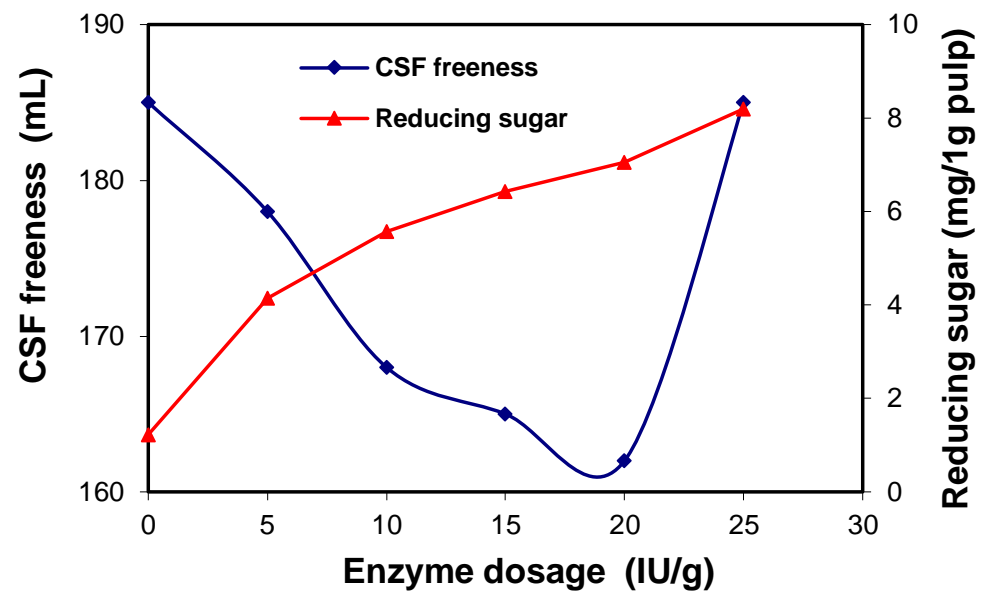

Fig. 3. Effect of cellulase loading on pulp freeness and reducing sugar at $20000 \mathrm{PFI}$ revolutions

Theoretically, in the enzyme loading vs. CSF freeness curves, pulp freeness should decrease with an increase of enzyme loading. During the enzymatic hydrolysis, pulp fibers were disintegrated into either shorter pieces (fiber shortening), or suffered external and internal laminations, even decomposed into small molecules (monosugars). Apparently, these effects are advantageous for fiber development. On the other hand, from Figs. 1, 2, and 3, a similar tendency is apparent: with the enzyme dosage increasing, the CSF freeness of the pulp was first decreased. Upon a certain enzyme loading, the pulp CSF increased. In other words, continuing to increase enzyme dosage to a certain point in pulp hydrolysis will increase the pulp drainage. With the lower dosage of enzyme in the pretreatment, all three enzymes (mannanase, xylanase, cellulase) will attack hemicellulose and cellulose in the pulp fibers, generating the fiber size reduction and yielding more fines in the pulps. In refining, the fines can decrease pulp drainage and pulp CSF. However, with the increase of enzyme loadings, degradation of very fine material (hemicellulose and fibrils most probably) will be lost during the pulp filtration in the CSF measurement, which would induce the CSF increase.

\section{Comparison of Reduction of PFI Revolutions under Optimized Enzyme Dosage}

In this step of study, the TMP pulps were first treated with the optimized enzyme dosage as discussed in the previous part, and then they were refined to different PFI revolutions, from 0 to 20000. For mannanase, xylanase and cellulase, the optimized dosages were $300 \mathrm{IU} / \mathrm{g}, 1000 \mathrm{IU} / \mathrm{g}$, and $20 \mathrm{IU} / \mathrm{g}$, respectively. Figures 4 and 5 show the relation between PFI revolutions and CSF freeness for mannanase and xylanase. In the case of mannanase, for a given freeness of control pulp, $185 \mathrm{~mL}$ at 20,000 revolutions, this freeness is equivalent enzyme-treated pulp at 16,000 revolutions. When using PFI revolutions as an energy indicator, from Fig. 4, mannanase-treated pulp was able to reduce energy consumption by 20\%. A similar case for xylanase (Fig. 5): $184 \mathrm{~mL}$ at 20000 
revolutions for the control pulp, which is equivalent enzyme-treated pulp at 15000 revolutions. In other words, xylanase-treated pulp was able to reduce energy consumption by $25 \%$.

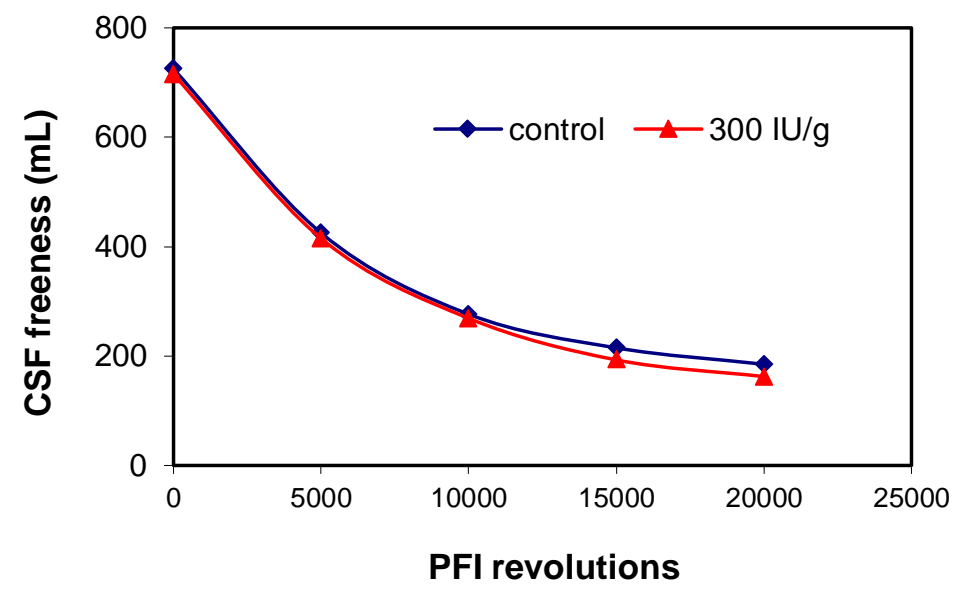

Fig. 4. PFI revolutions vs. pulp freeness on mannanase pretreated pulps

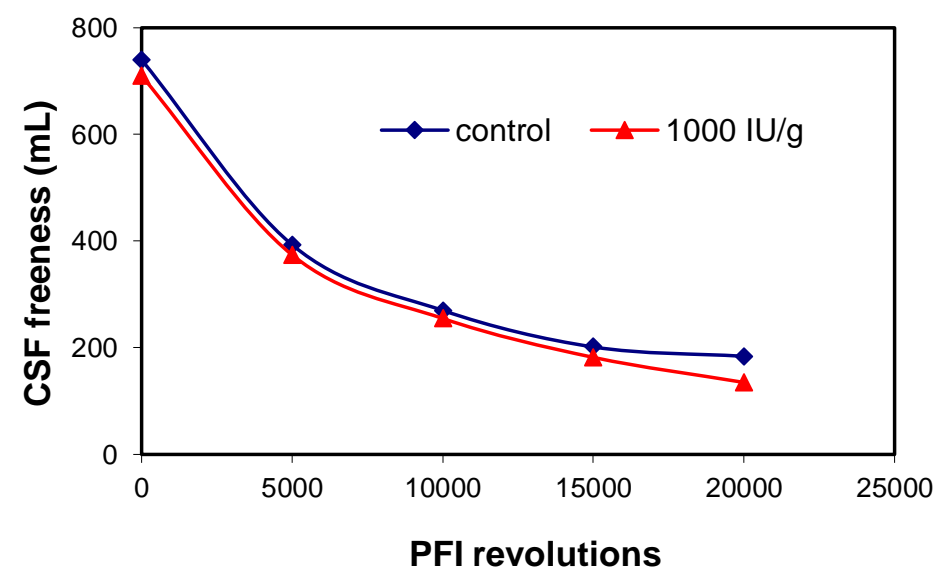

Fig. 5. PFI revolutions vs. pulp freeness on xylanase pretreated pulps

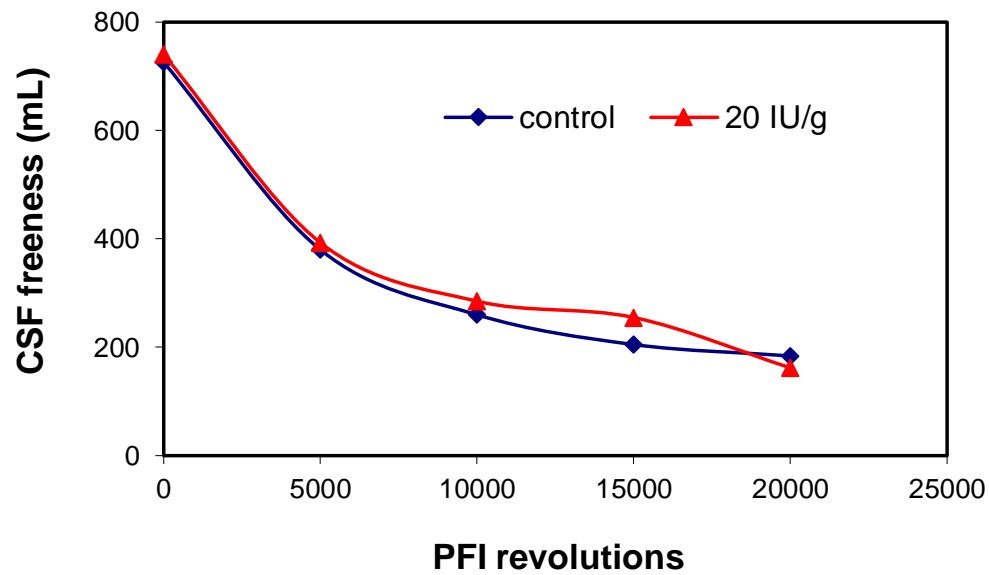

Fig. 6. PFI revolutions vs. pulp freeness on cellulase pretreated pulps 
Figure 6 shows the relation between PFI revolutions and CSF freeness of a cellulase-treated pulp. Contrary to mannanase and xylanase, there was no significant energy savings for cellulase-treated pulp. Although there was a slight decrease in CSF freeness at 20000 revolutions, globally no clear trends could be observed in the cellulasetreated pulp when compared with the control pulp.

\section{Effect of Hydrolysis Time}

Different hydrolysis times, from 1 to $6 \mathrm{~h}$, were applied using the optimized enzyme loading pulps. Figures 7, 8, and 9 show the effect of hydrolysis time on pulp freeness and reducing sugar. For mannanase, pulp freeness and reducing sugar were almost the same in different hydrolysis times from 1 to $6 \mathrm{~h}$. A similar tendency can also be seen in xylanase except for a slight sugar increase in the $6^{\text {th }}$ hour of hydrolysis. But for the quantity of reducing sugar, xylanase ( $1.5 \mathrm{mg} / 1 \mathrm{~g}$ o.d. pulp) yielded much less than mannanase $(4 \mathrm{mg} / 1 \mathrm{~g}$ o.d. pulp).

It is interesting to see the cellulase case: with the increase of hydrolysis time, there was an evident increase of pulp freeness but no change in reducing sugar. It can be speculated that, with the increase of hydrolysis time, cellulase can increase pulp drainage, probably due to the increase of fines (Oksanen et al. 2000). As a result, pulp freeness decreases. Combined with Figs. 7, 8, and 9, the hydrolysis time had no significant effect on pulp freeness (except cellulase) and reducing sugar. This would seem to indicate that the initial one hour treatment is enough for pulp hydrolysis.

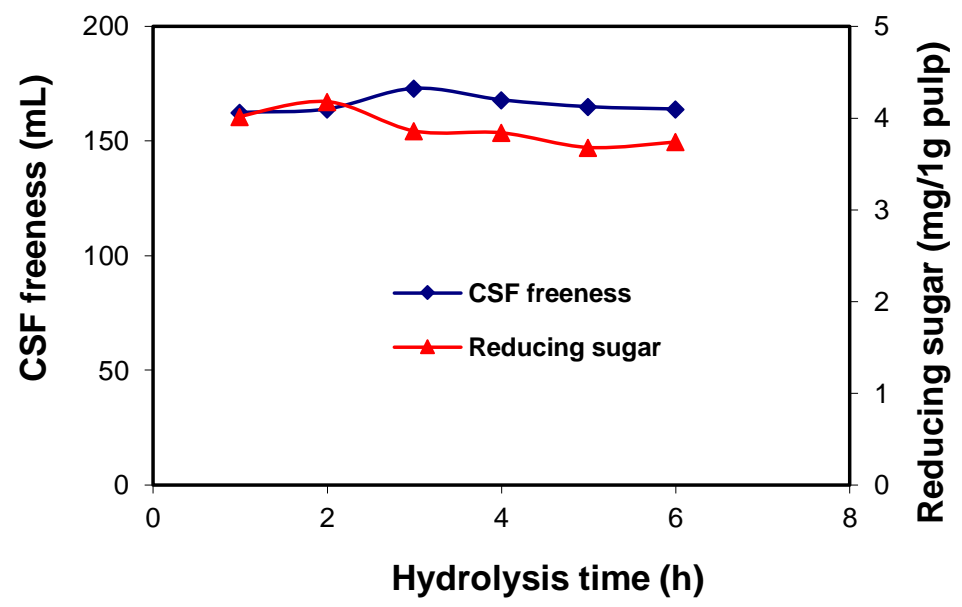

Fig. 7. Effect of mannanase hydrolysis time on pulp freeness and reducing sugar 


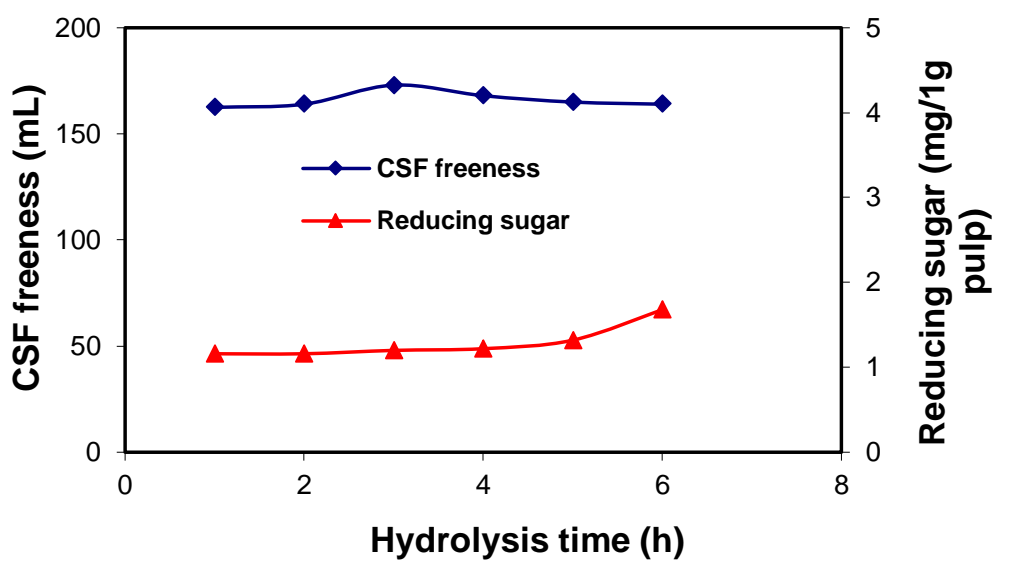

Fig. 8. Effect of xylanase hydrolysis time on pulp freeness and reducing sugar

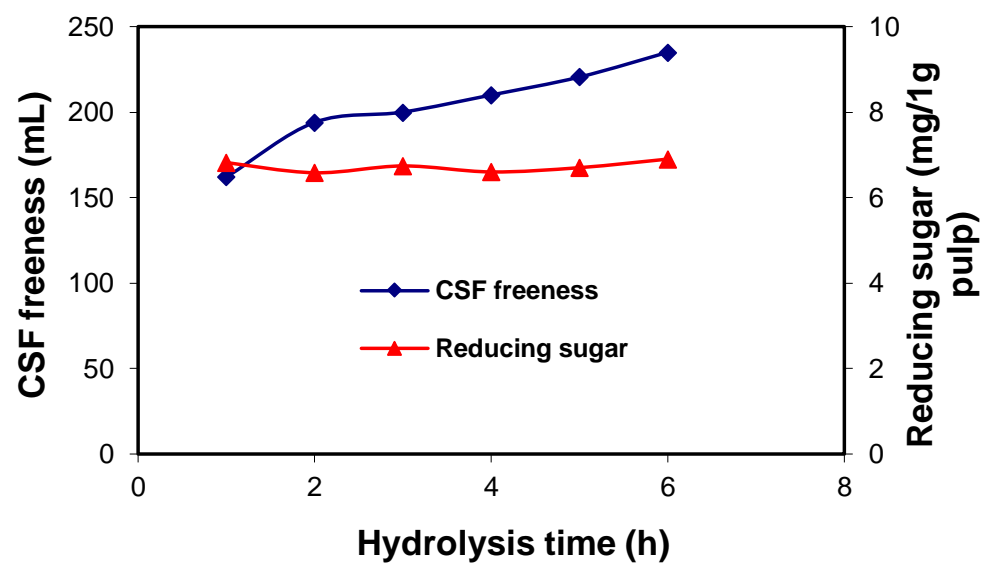

Fig. 9. Effect of cellulase hydrolysis time on pulp freeness and reducing sugar

\section{Effect of Enzyme Hydrolysis on Fiber Morphology}

Figures 10, 11, and 12 show the effect of enzymatic hydrolysis on fiber length and fines content. Regardless of the enzyme loading, all the three hydrolysis conditions had similar effects on pulp fibers: with an increase of enzyme dosage, fiber length decreased gradually and reached a plateau. There was significant difference in fiber length reduction among the three enzymes, i.e. maximum was in the range of 10 to $12 \%$. Similar results were obtained for the fines production: with increasing enzyme loading, fines content increased continuously and then leveled off.

The maximum increase of fines content in the pulp for these three enzymes was in the range of 22 to 35\%. Mannanase and xylanase yielded fewer fines (about 30\%) than cellulase (about 35\%). It can be observed from these three figures that the enzyme loading at the point of maximum fiber length reduction and fines increase was very close to the optimal point in the enzyme hydrolysis experiments (Figs. 1, 2, and 3). In the comparison in this point for fiber length reduction and fines content, among these three enzymes, xylanase was less efficient in fiber breakdown (fiber shortening and fines production), mannanase in the middle, and cellulase was the most efficient. In other words, within the same enzyme loading, it was easier for cellulase than mannanase and xylanase to disintegrate and degrade pulp fibers during hydrolysis. 


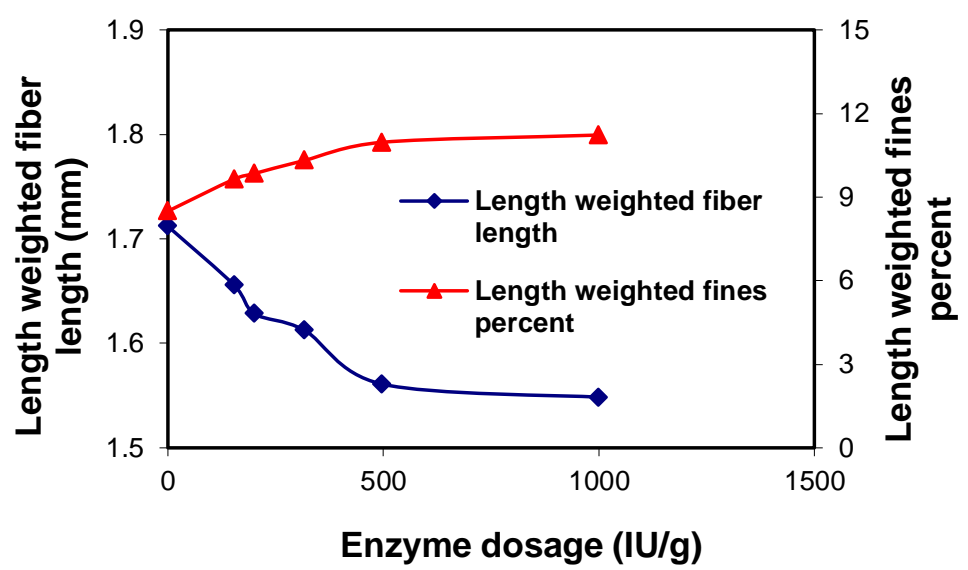

Fig. 10. Effect of mannanase loading on fiber length and fines content

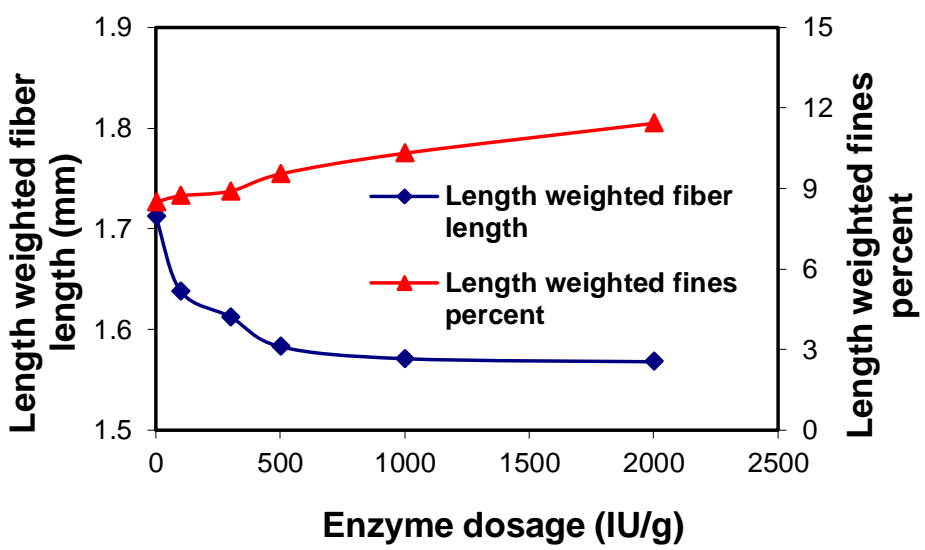

Fig. 11. Effect of xylanase loading on fiber length and fines content

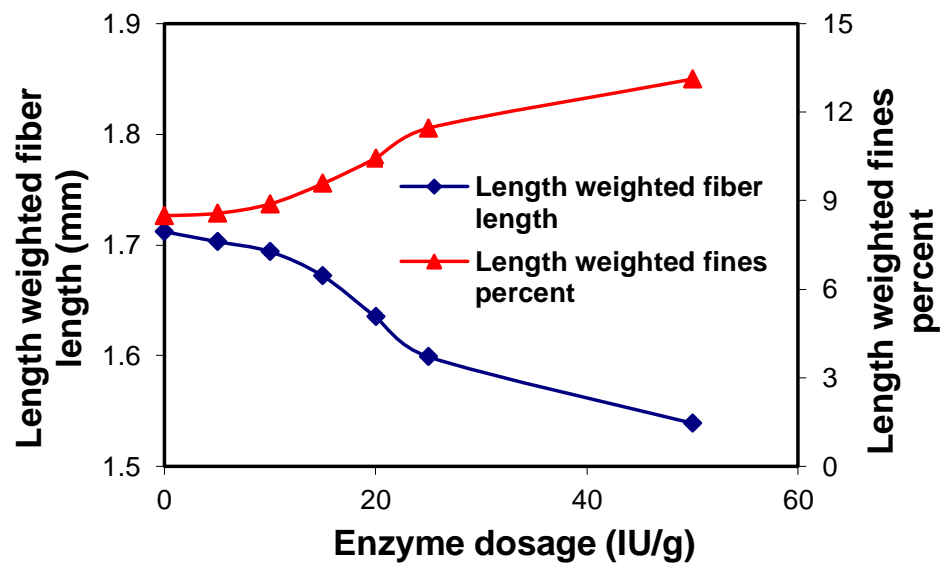

Fig. 12. Effect of cellulase loading on fiber length and fines content

\section{Water Retention Value (WRV)}

The water retention value (WRV) of pulp is related to fiber internal fibrillation and fines content (Oksanen et al. 2000). Higher fiber internal fibrillation and fines content will increase pulp WRV. Figures 13, 14, and 15 show the effect of enzyme dosage on pulp WRV and fines contents for mannanase, xylanase, and cellulase treated pulps, respectively. A similar tendency can be noticed from these figures: with an increase in enzyme dosage, 
all pulp WRV decreased. It can be found that pulp WRV decreased with the increase of fines content in pulps. One possible explanation for this phenomenon is that during the hydrolysis, enzyme attacks and degrades the fibers, which yields more fines. During the WRV measurement, parts of the fines were removed from the wire during the centrifugation. Considering the same operation for all pulps, the effect of fines filtering can be regarded same for all enzymatic hydrolysis. Thus, more hydrolysis in the pulp results in more fines being removed. That might be reason that the WRV decreases with the enzyme loading. Furthermore, another tendency can be noticed in these figures: the WRVs dropped rapidly in the low enzyme loadings, and subsequently they remained almost constant. The transition points in the WRV curves were very close to the optimized enzyme loading, which indirectly demonstrated that further increase of enzyme has no effect for the pulp hydrolysis.

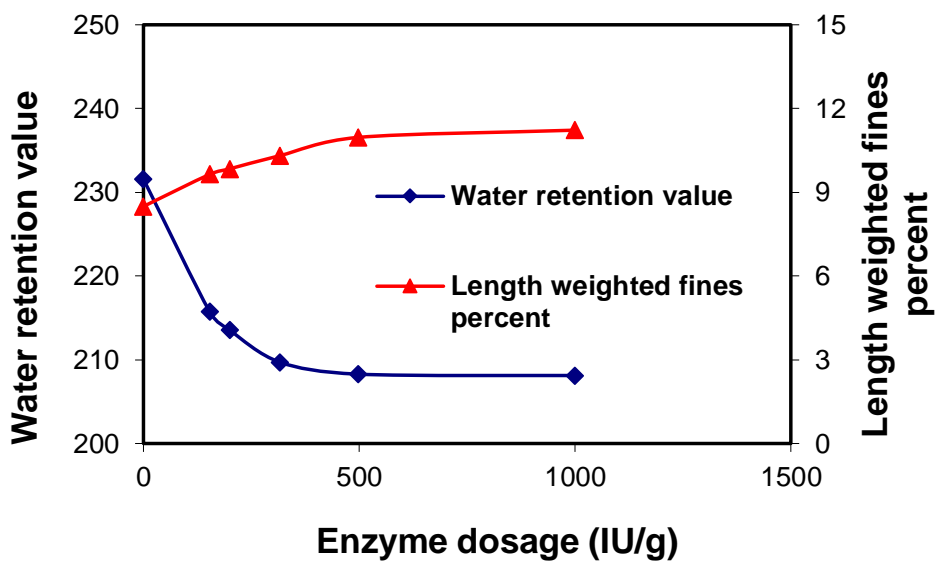

Fig. 13. Effect of mannanase loading on water retention value and fines content

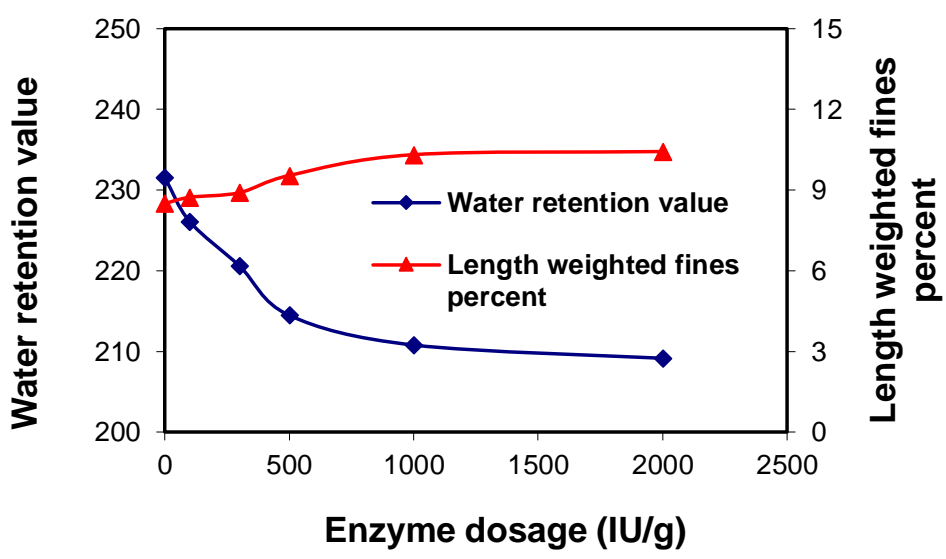

Fig. 14. Effect of xylanase loading on water retention value and fines content 


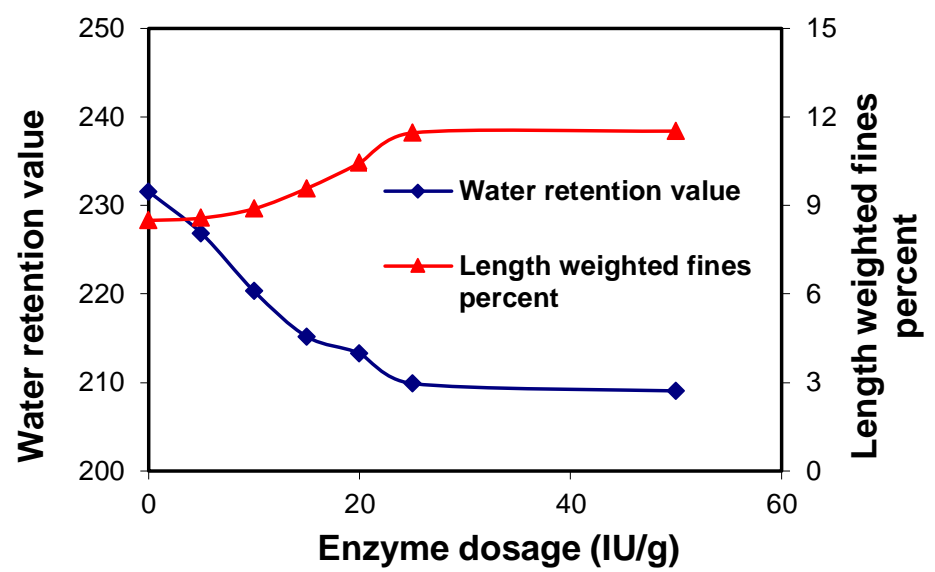

Fig. 15. Effect of cellulase loading on water retention value and fines content

\section{Tensile Strength}

Figures 16, 17, and 18 show the effect of enzyme dosage on pulp tensile index for mannanase, xylanase, and cellulase, respectively. It can be seen that the tensile index of all the pulps was slightly decreased $(\sim 3 \%)$ with the increase of enzyme loadings. The tensile strength of the TMP pulp was mainly influenced by the fibril-like fines. Although the enzymes promoted the increase of fines during the treatment, these fines were washed out during the filtration, as discussed in the WRV results. Another possible cause might be the degradation of very fine material (hemicellulose and fibrils most probably) by the enzymatic treatment. Due to these reasons, the decrease of these fines in the filtered pulps induced the minor decrease of the tensile strength.

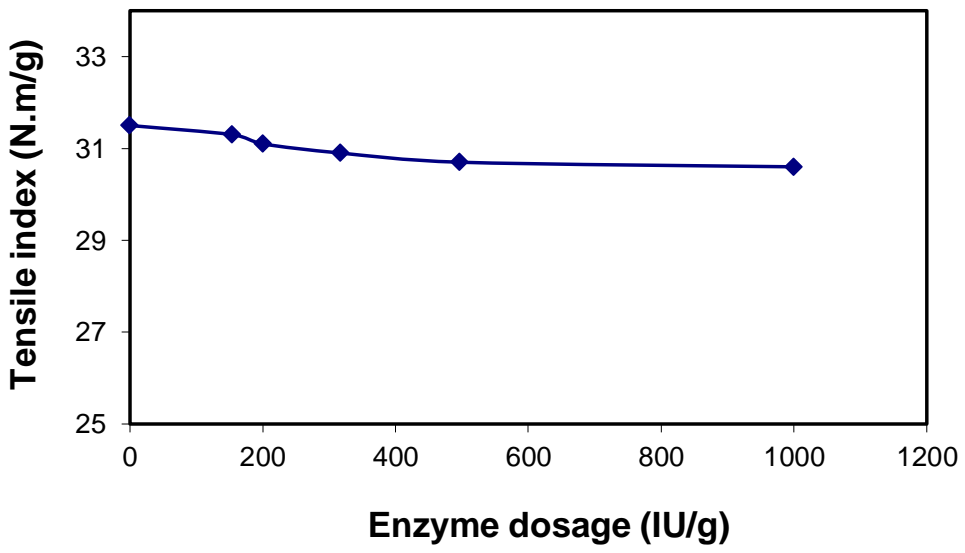

Fig. 16. Mannanase loading vs. tensile index 


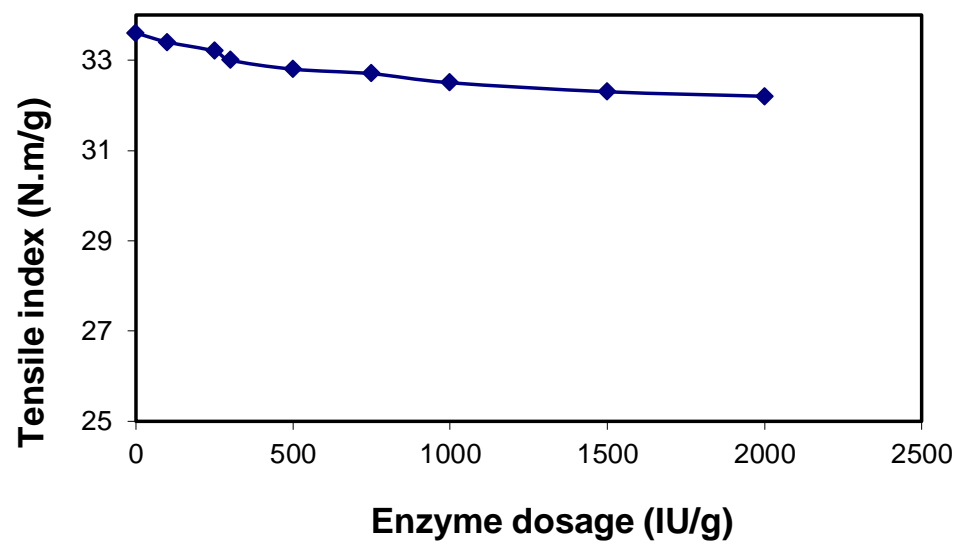

Fig. 17. Xylanase loading vs. tensile index

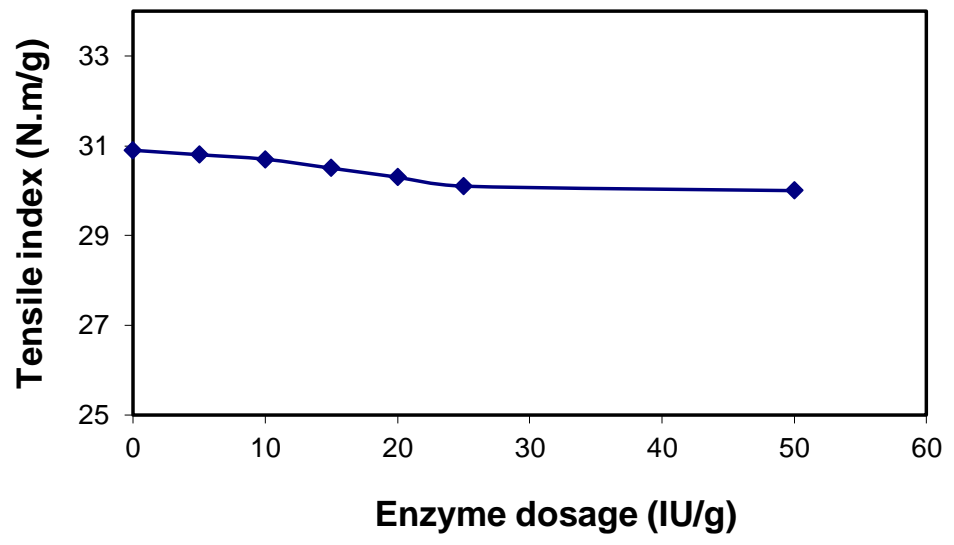

Fig. 18. Cellulase loading vs. tensile index

\section{CONCLUSIONS}

1. Under the optimized enzyme loadings for the thermomechanical pulp (TMP) primary discharge fibers, in comparison with the control pulp, mannanase and xylanase pretreatment could save PFI beating revolutions by $20 \%$ and $25 \%$, respectively. There was no significant reduction of PFI revolution for the cellulase-treated pulp.

2. During the hydrolysis, enzymes could break down TMP fibers into shorter pieces and yield more fines than the control pulp. Under optimized enzymes loadings, the fiber length was reduced by 10 to $12 \%$ and the fines production was increased by 30 to $45 \%$ among these three enzymes. However, among these three enzymes, cellulase showed higher efficiency in fiber breakdown, mannanase in the middle, and xylanase the lowest. On the other hand, since the fines produced during in the hydrolysis were washed out, there was no significant difference in the pulp water retention values for these three enzyme-treated pulps.

3. As for the effect of hydrolysis time, longer times (more than one hour) had no evident effect on pulp freeness reduction or reducing sugar production. This indicates that one hour hydrolysis would be enough for enzymatic treatment. Among these three 
enzymes, under the optimized enzyme loading, cellulase was the most efficient in reducing sugar production, mannanase in the middle, and xylanase produce the least.

\section{ACKNOWLEDGMENTS}

The authors would like to gratefully acknowledge the financial support provided by the National Natural Science Foundation of China (No. 31270638), the guide project from Department of Science and Technology of Fujian Province (2018H0006), and the Foundation (No. KF201922) of State Key Laboratory of Biobased Material and Green Papermaking, Qilu University of Technology, Shandong Academy of Sciences.

\section{REFERENCES CITED}

Adney, B. and Baker, J. (1996). "Measurement of cellulase activities," in: Laboratory Analytical Procedure, Golden, CO: National Renewable Energy Laboratory.

Allender, B. M., and Waterhouse, J. F. (1986). "Morphological factors in the refining of eucalypt and Pinus radiata fibers," in: PIRA Int. Conf. New Technologies in Refining, Birmingham, England, 2(3), Paper 8, p. 22.

Bailey, M. J., Biely, P., and Poutanen, K. (1992). "Interlaboratory testing of methods for assay of xylanase activity,” J. Biotechnol. 23(3), 257-270. DOI: 10.1016/01681656(92)90074-J

Bajpai, P., Mishira, S. P., Mishira, O. M. P., Kumar, S., and Bajpai, P. K. (2006). "Use of enzyme for reduction in refining energy - laboratories studies," Tappi J. 5(11), 25-32.

Bhardwaj, N. K., Bajpai, P., and Bajpai, P. K. (1996). "Use of enzymes in modification of fibers for improved beatability," J. Biotechnol. 51(1), 21-26. DOI:10.1016/01681656(96)01556-8

Bhat, M. K. (2000). "Cellulases and related enzymes in biotechnology," Biotechnol. Adv. 18(5), 355-383. DOI:10.1016/S0734-9750(00)00041-0

Hart, P. W., Waite, D. M., Thibault, L., Tomashek, J., Rousseau, M-E., Hill, C., and Sabourin, M. J. (2009). "Selective enzyme impregnation of chips to reduce specific refining energy in alkaline peroxide mechanical pulping," Holzforschung 63(4), 418423. DOI: $10.1515 /$ HF.2009.065

Huang, F., Singh, P. M., and Ragauskas A. J. (2011). "Characterization of milled wood lignin (MWL) in Loblolly pine stem wood, residue, and bark," J. Agri. \& Food Chem, 59(24), 12910-12916. DOI: 10.1021/jf202701b

Lei, X., Lin, L., and Li, K. (2008). "Effect of xylanase pretreatment of wood chips on fiber separation in the CTMP refining process," Bioresources 3(3), 801-815. DOI: 10.15376/biores.3.3.801-815

Mansfield, S. D., Wong, K. K. Y., and Richardson, J. D. (1999). "Improvements in mechanical pulp processing with proteinase treatments," Appita J. 52(6), 436-440.

Miller, G. L. (1959). "Use of dinitrosalicylic acid reagent for determination of reducing sugar," Analytical Chem. 31(3), 426-428. DOI: 10.1021/ac60147a030

Oksanen, T., Pere, J., Paavilainen, L., Buchert, J., and Viikari, L. (2000). "Treated of recycled kraft pulps with Trichoderma reesei hemicellulase and cellulase," $J$.

Biotechnol. 78, 39-48. DOI:10.1016/S0168-1656(99)00232-1 
Peng, F., Ferritsius, R., and Angsas, U. (2005). "Method of producing mechanical pulp and the mechanical pulp thus produced," U.S. Patent No. 2005/0241785 A1.

Petit-Conil, M., Hoddenbagh, M. A., Meyer, V., and Tolan, J. (2005a). "Can enzymes really be used to reduce chip refining energies? A study of xylanase pre-treatment of hardwood chips," in: International Mechanical Pulping Conference, Oslo, Norway, pp. 233-239.

Petit-Conil, M., Hoddenbagh, M. A., and Tolan, J. S. (2005b). "Method for mechanical pulp production," U.S. Patent No. 20090107643 A1.

Pere, J., Siika-Aho, M., and Viikari, L. (2000). "Biomechanical pulping with enzymes: Response of coarse mechanical pulp to enzymatic modification and secondary refining," Tappi J. 83, 1-8.

Pere, J., Ellmen, J., and Viikari, L. (2007). "Process for preparing mechanical pulp," U.S. Patent No. 20070151683 A1.

Rättö, M., and Poutanen, K. (1988). "Production of mannan-degrading enzymes," Biotechnol. Let. 10(9), 661-664 (1988). DOI: 10.1007/BF01024721

Richardson, J. D. (1996). "The DWS (Dilution Water Sulfonation) process: The effect of pulping conditions on pulp quality,"Appita J. 49(27), 27- 32.

Richardson, J. D., Wong, K. K. Y., and Clark, T. A. (1998). "Modification of mechanical pulp using carbohydrate-degrading enzymes," J. Pulp Pap. Sci. 24, 125-129.

Setliff, E., Marton, R., Granzow, S. G., and Eriksson, K.-E. (1990). "Biomechanical pulping with white-rot fungi," Tappi J. 73, 141-147.

Sluiter, A., Hames, B., Ruiz, R., Scarlata, C., Sluiter, J, Templeton, D., and Crocker, D. (2008). "Determination of structural carbohydrates and lignin in biomass," in: Laboratory Analytical Procedure, Golden, CO: National Renewable Energy Laboratory.

Article submitted: January 22, 2015; Peer review completed: March 18, 2015; Revised version received and accepted: August 6, 2020; Published: August 12, 2020.

DOI: 10.15376/biores.15.4.7487-7502 